\title{
EVOLUÇÃO DO ESTADO FISIOLÓGICO DA PARTE AÉREA DO MORANGUEIRO DURANTE A ARMAZENAGEM EM CÂMARA FRIGORÍFICA ${ }^{1}$
}

\author{
GILBERTO LUIZ PUTTI², RÉMY RAGEAU ${ }^{3}$, MARC BONHOMME ${ }^{3}$, GABRIEL BERENHAUSER LEITE ${ }^{4}$, \\ GILLES PETEL 5
}

\begin{abstract}
RESUMO - O objetivo deste trabalho foi avaliar o estado fisiológico da parte aérea das plantas de morangueiro das cultivares Gariguette e Elsanta durante estocagem em câmara fria $\left(-2^{\circ} \mathrm{C}\right)$, de janeiro a agosto. Pelo teste biológico, a capacidade de crescimento manteve-se alta, sem evolução significativa durante a estocagem. O fluxo de calor metabólico $(\mathrm{Q})$ e a intensidade respiratória $\left(\mathrm{RCO}_{2}\right)$ dos tecidos da zona apical, medidos pela microcalorimetria na saída da câmara fria, não evoluíram significativamente, mas aumentaram após 48 e 72 horas de aclimatação a $20^{\circ} \mathrm{C}$. Existiu um estreito paralelismo entre os valores de $\mathrm{Q}$ e $\mathrm{RCO}_{2}$ e da umidade ponderal (UP) dos tecidos. A parte aérea das plantas manteve a capacidade de crescimento mesmo após oito meses de estocagem.
\end{abstract}

Termos para Indexação: microcalorimetria, calor metabólico, respiração, umidade ponderal, capacidade de crescimento, teste biológico.

\section{EVOLUTION OF PHYSIOLOGICAL STATE OF THE AERIAL PART OF STRAWBERRY PLANTS DURING COLD STORAGE}

\begin{abstract}
The aim of this work was to know the physiological state of the aerial part of strawberry plants (varieties Gariguette and Elsanta) during storage in cold chamber $\left(-2^{\circ} \mathrm{C}\right)$ from January until August. According to the biological test (petiole test), the growth capacity was kept up without significant evolution. The flow of metabolic heating $(\mathrm{Q})$ and the respiratory intensity $\left(\mathrm{RCO}_{2}\right)$ of the apical zone tissues measured at the exit of the cold chamber did not change significantly. Their values measured after 48 and 72 hours of acclimatization at $20^{\circ} \mathrm{C}$ were higher than at the exit of the cold chamber. The differences between the values without acclimatization and after acclimatization increased during the first weeks of storage, showing an evolution in the apex of the plant. There was a strict parallelism between the values of Q and RCO2 and of the tissues water contents (UP). The growth capacity of the aerial part of the plants seemed to keep up even after 8 months of storage.
\end{abstract}

Index Terms: strawberry plant, microcalorimetric method, metabolic heating, respiration, water content, growth capacity, biological test.

A qualidade da muda tem influência sobre o desenvolvimento do morangueiro e a produção de morangos. Na Europa, onde o plantio do morangueiro pode ser feito desde o inverno, com a utilização de estufas aquecidas, até o verão (Lieten et al., 1995), as mudas passam geralmente por um período de frio natural (podem também receber frio artificial para a quebra da dormência). Se não forem plantadas em seguida, são estocadas em câmaras frigoríficas, como é o caso das planta chamadas plants frigo.

Para verificar as diferenças do potencial de crescimento do morangueiro, utiliza-se atualmente de um teste biológico conhecido como teste do pecíolo (Robert et al., 1997). Este teste é baseado no crescimento dos pecíolos das folhas em condições climáticas adequadas ao crescimento (temperatura e fotoperíodo), onde o menor desenvolvimento dos pecíolos indicaria a diminuição do potencial de crescimento, enquanto o maior crescimento dos pecíolos indicaria a retomada do potencial de crescimento. Este teste geralmente é usado como indicador da dormência das gemas do morangueiro. Um ponto negativo deste teste é o tempo para obter a resposta, que varia entre 45 e 120 dias.

Uma melhor condução do sistema de produção de morangueiros implica o conhecimento do estado fisiológico e, em particular, da capacidade de crescimento da planta nas diferentes etapas de produção. As diferenças na atividade fisiológica dos tecidos e órgãos podem ser parametradas pelo fluxo respiratório $\left(\mathrm{CO}_{2}\right.$ emitido e/ou $\mathrm{O}_{2}$ absorvido) e/ou pelo fluxo de calor metabólico liberado. Segundo Hansen et al. (1989), a combinação destes dois parâmetros pode caracterizar a capacidade de crescimento (parte da energia fornecida pela respiração empregada no crescimento). A técnica de microcalorimetria permite medir estes fluxos de calor rapidamente em pequenas quantidades de material, possibilitando uma amostragem repetitiva na mesma planta.

As condições de temperatura durante as horas e/ou dias que precedem as medições podem influenciar nos parâmetros das determinações microcalorimétricas. A possibilidade de aclimatação do material vegetativo para padronizar estas condições são possíveis, mas depende de serem estudadas.

Atualmente, as mudas são classificadas e comercializadas para o plantio somente pelo diâmetro na base da planta (rizoma). A constante procura por outros parâmetros que auxiliem nesta classificação se faz necessária, pois os métodos até hoje utilizados, como a medida dos teores de nucleotídeos (Robert, 1996) e o teste biológico (Robert et al., 1997), mostram alguma impertinência no seu emprego rotineiro.

O objetivo deste trabalho foi avaliar a evolução da qualidade fisiológica das mudas de morangueiro durante a fase de estocagem utilizando: microcalorimetria (emissão de calor metabólico (Q) e taxa respiratória $\left(\mathrm{RCO}_{2}\right)$ ), umidade ponderal e teste biológico de crescimento da partea aérea das plantas. Nas medidas microcalorimétricas e umidade ponderal, a avaliação do estado das plantas apoiou-se sobre medidas feitas em plantas logo após a saída da câmara fria e também em plantas que passaram por uma curta aclimatação ( 48 e 72 horas) à temperatura de $20^{\circ} \mathrm{C}$.

O trabalho foi desenvolvido em Clermont-Ferrand, centro da França, com as cultivares de morangueiro Gariguette e Elsanta, no ano de 2003. As plantas tipo plants frigo de raízes nuas, das duas cultivares, foram arrancadas do campo, ensacadas em sacos plásticos e armazenadas a $-2^{\circ} \mathrm{C}( \pm 0,5)$, no dia $07-01-2003$. As plantas foram colocadas em câmara frigorífica em pleno inverno quando há forte probabilidade de estas estarem em repouso invernal (endo ou ecodormentes).

Os seguintes parâmetros foram analisados:

1. Medidas microcalorimétricas. As zonas de crescimento da planta de morangueiro (meristema e os primórdios foliares e florais) foram extraídas e inseridas no microcalorímetro. Após a estabilização e a determinação da emissão de calor metabólico (aproximadamente 20

\footnotetext{
' (Trabalho 019/2005). Recebido: 13/01/2005. Aceito para publicação: 05/08/2005. Parte de trabalho de doutorado financiado pela Capes - Cofecub, Ciref e UBP. ${ }^{2}$ Eng. Agr. M.Sc. Doutorando - Bolsista CAPES/Brasil. Endereço: UMR PIAF, INRA Domaine de Crouelle 234 avenue du Brézet F63039 Clermont-Ferrand Cedex France.E-mail: gputti@clermont.inra.fr.

${ }^{3}$ Eng. Agr. Dr. UMR PIAF, INRA Domaine de Crouelle 234 avenue du Brézet 63039 Clermont-Ferrand Cedex 2 France. E-mails: rageau@clermont.inra.fr; bonhomme@clermont.inra.

${ }^{4}$ Eng. Agr. Dr. EPAGRI/UnC CP 591, Caçador, SC, Brasil 89500-000. E-mail: gabriel@epagri.rct-sc.br.

${ }^{5}$ Professor Dr. UMR PIAF, UBP Les Cézeaux, 24 avenue des Landais 63177 Aubière France. E-mail: gilles.petel@sciences.univ-bpclermont.fr.
} 
minutos), inseriu-se uma cápsula com $20 \mu \mathrm{L}$ com solução de $\mathrm{NaOH}$ a 1 $\mathrm{N}$ que reage com o $\mathrm{CO}_{2}$ liberado pela respiração da planta, resultando num adicional de calor. Após nova estabilização e determinação, utilizaram-se estes valores para o cálculo da taxa respiratória. Os valores foram sempre relacionados ao peso seco do material. As medidas microcalorimétricas foram feitas uma vez por mês a 18 e $20^{\circ} \mathrm{C}$ (temperatura de medida no microcalorímetro), em diferentes tempos de aclimatação, $0 ; 48$ e 72 horas a $20^{\circ} \mathrm{C}$ ), com 3 repetições (plantas) por tratamento.

2.Umidade ponderal. Foi calculada sobre o mesmo material que se utilizou nas medidas microcalorimétricas. A cada determinação, pesouse a cada medida o peso fresco e o peso seco, depois se efetuou o cálculo, com seis repetições.

3.Teste biológico de capacidade de crescimento (teste do pecíolo). A cada data de medição microcalorimétrica, colocaram-se cinco plantas em sala de crescimento a $25^{\circ} \mathrm{C}$ durante o dia e $15^{\circ} \mathrm{C}$ durante a noite e fotoperíodo de 12 horas. A cada 15 dias, os pecíolos emitidos foram marcados com barbante de cor diferente, e no fim de quatro meses efetuou-se a medida de comprimento de pecíolo. Para o cálculo do comprimento final do pecíolo, foram usados todos os pecíolos emitidos até o final do primeiro mês.

4. Necrose da cv. Gariguette. As observações das plantas com necrose interna foram feitas no momento de extração do ápice meristemático.

As médias foram comparadas entre si pelo teste de Duncan para determinar a diferença dos tempos de aclimatação em cada data de avaliação. Para determinar as diferenças nas dinâmicas para cada curva, os dados foram submetidos à análise de regressão linear.

O fluxo de calor metabólico (Q) tem dinâmica semelhante ao fluxo respiratório $\left(\mathrm{RCO}_{2}\right)$, nas duas temperaturas medidas, mas os valores são maiores a $20^{\circ} \mathrm{C}$ que a $18^{\circ} \mathrm{C}$ (Figura 1 ).

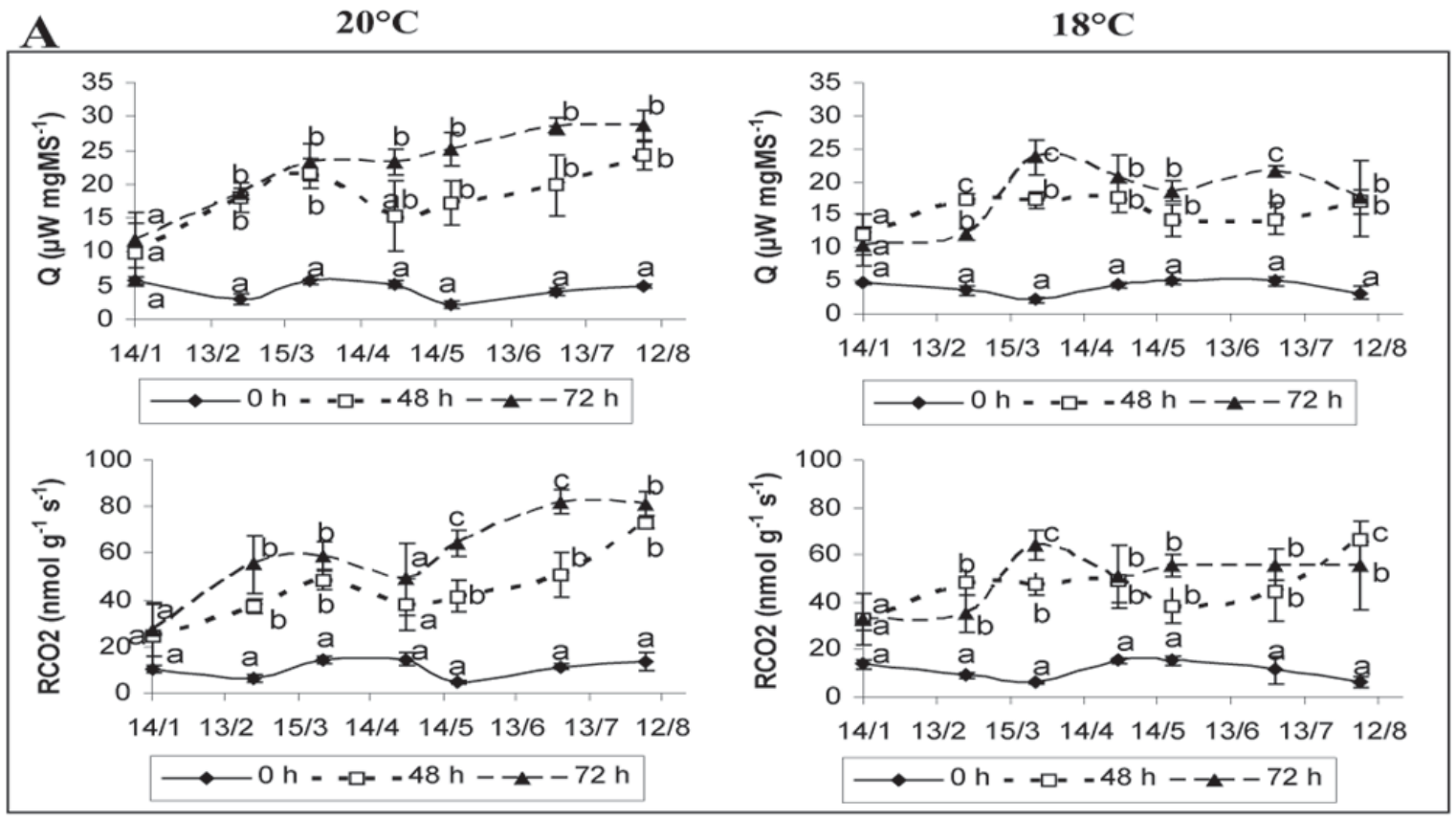

B

$20^{\circ} \mathrm{C}$

$18^{\circ} \mathrm{C}$
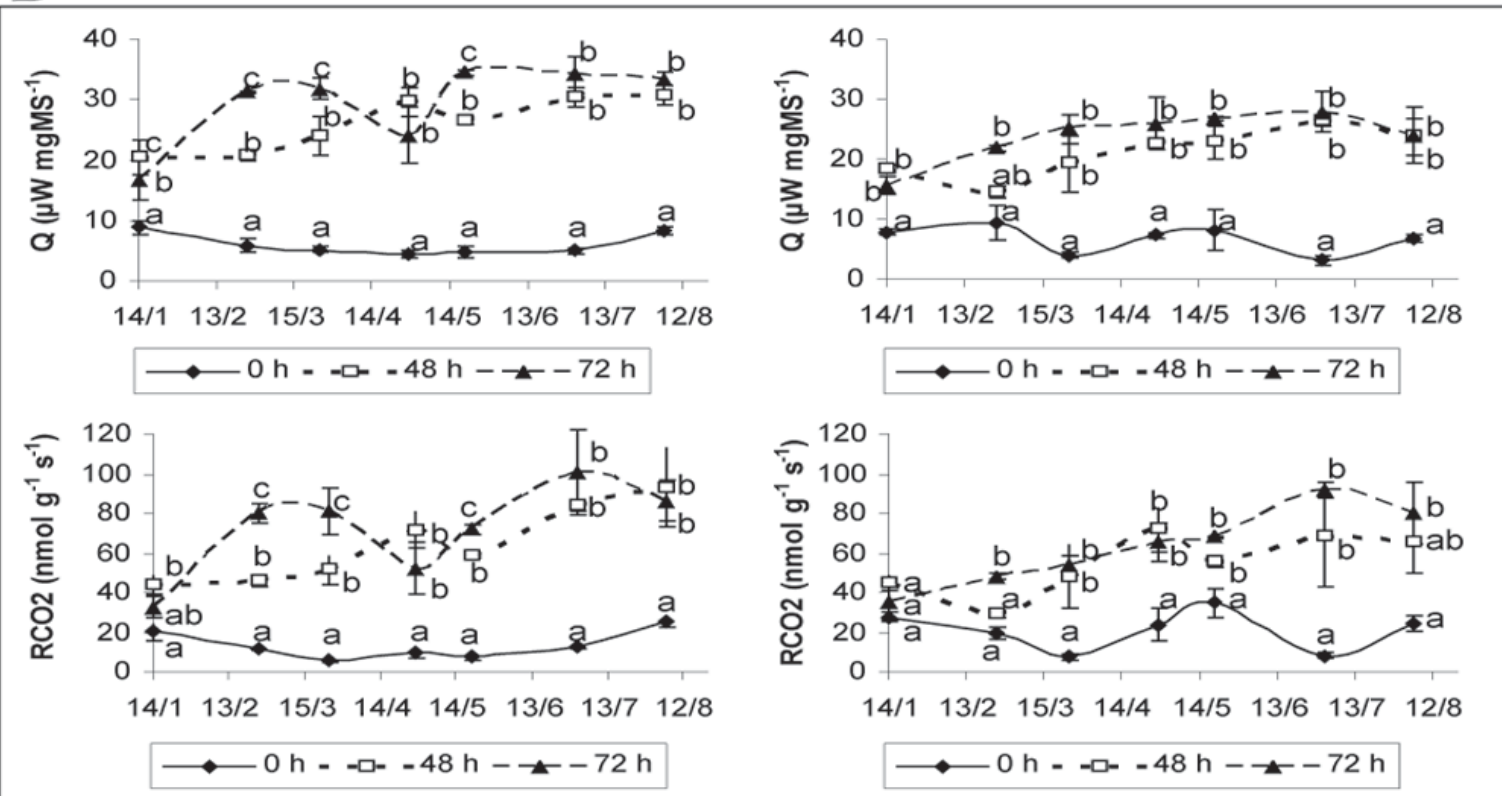

FIGURA 1 - Emissão de calor metabólico (Q) e fluxo respiratório (RCO2) de gemas das cvs. Gariguette (A) e Elsanta (B) em 2003 , medidas a 18 e $20^{\circ} \mathrm{C}$ após $0 ; 48$ ou 72 horas de aclimatação a $20^{\circ} \mathrm{C}$. As barras representam o erro-padrão. Letras iguais na mesma data não apresentam diferenças estatísticas entre si, pelo teste de Duncan, a 5\% de probabilidade, para 0; 48 e 72 horas de aclimatação 


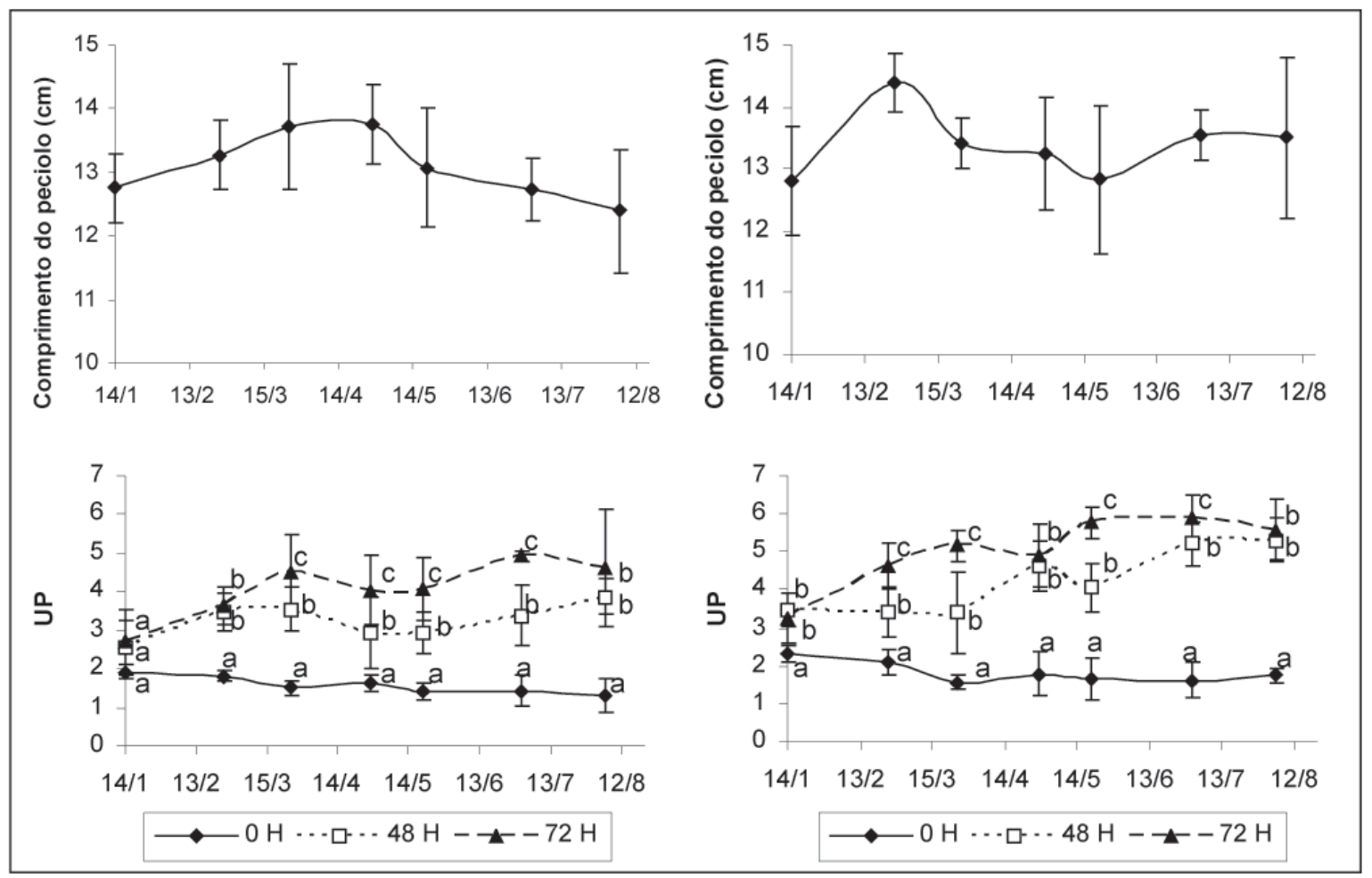

FIGURA 2 - Comprimento dos pecíolos após 4 meses e umidade ponderal (UP) das gemas, nas cvs. Gariguette e Elsanta, em 2003 , após 0 ; 48 ou 72 horas de aclimatação a $20^{\circ} \mathrm{C}$. As barras representam o erro-padrão. Letras iguais na mesma data não apresentam diferenças estatísticas entre si, pelo teste de Duncan, a 5\% de probabilidade, para 0; 48 e 72 horas de aclimatação.

A energia direcionada ao crescimento, também chamada de potencial de crescimento (Rsgähb), pode ser calculada segundo as fórmulas já desenvolvidas em um certo número de artigos sobre a energética celular (Criddle et al., 1991; Hansen et al., 1996), utilizando Q e $\mathrm{RCO}_{2}$. Este cálculo acumula os erros de medidas de cada um dos parâmetros $\left(\mathrm{Q}\right.$ e $\left.\mathrm{RCO}_{2}\right)$ que apresentam forte variabilidade. Sendo assim, para se ter uma cálculo confiável, é necessário um número adequado de repetições. Segundo Henry (1999), o número de medidas necessárias para se ter um RsgÄhb confiável no morangueiro variaria entre 11 e 80 repetições, dependendo do tipo de planta e estado fisiológico. Esta quantidade de repetições é praticamente impossível de ser realizada, utilizando-se de um microcalorímetro com uma única célula de medição. Por este motivo, o RsgÄhb foi desconsiderado neste trabalho.

No tratamento sem aclimatação das plantas $(0 \mathrm{~h})$, os valores de $\mathrm{Q}$ e $\mathrm{RCO}_{2}$ da zona de crescimento não evoluíram significativamente durante a armazenagem, mesmo ao fim de oito meses. A aclimatação a 20 ${ }^{\circ} \mathrm{C}$, por 48 e 72 horas, aumentou os valores de $\mathrm{Q}$ e $\mathrm{RCO}_{2}$. Esta resposta à aclimatação pode ser interpretada como um tempo mínimo para a reativação do metabolismo da planta, visto que estas estavam armazenadas a $-2^{\circ} \mathrm{C}$. Há uma tendência de que os valores a 72 horas de aclimatação sejam maiores que os valores a 48 horas, mas as diferenças não foram significativas na maioria das datas amostradas (Figura 1).

As diferenças entre os valores de $\mathrm{Q}$ e $\mathrm{RCO}_{2}$ medidos sem aclimatação e após aclimatação aumentaram durante os dois primeiros meses de estocagem no frio, traduzindo uma mudança no estado do ápice meristemático.

O conteúdo de água na planta (umidade ponderal), no tratamento sem aclimatação, diminuiu significativamente $(p<0,01)$ com a armazenagem, nas duas cultivares (Figura 2). Já nos tratamentos de 48 e 72 horas de aclimatação, o conteúdo de água aumentou significativamente $(\mathrm{p}<0,05)$ nos primeiros dois meses de armazenagem (março/abril), mantendo-se, após, estável até o final do período de armazenagem. Foi observado um paralelismo entre a evolução dos valores de $\mathrm{Q}$ e $\mathrm{RCO}_{2}$ com a evolução da umidade ponderal (Figuras 1 e 2).

O teste do pecíolo indicou variações na capacidade de crescimento da parte aérea durante a armazenagem em câmara fria (Figura 2), em particular um aumento inicial (prolongando-se durante 3 meses na cv. Gariguette, e somente 1 mês na cv. Elsanta), depois uma estabilização (Elsanta), ou uma diminuição (Gariguette). Contudo, é difícil deduzir se este aumento inicial dos valores se trata do fim da saída da dormência que não teria terminado no momento da entrada das plantas em câmara fria. $\mathrm{Na}$ verdade, o tamanho do pecíolo está em nível considerado alto (durante o período de plena endodormência, por exemplo, o tamanho do pecíolo pode ficar muito menor, podendo chegar a mais ou menos $3 \mathrm{~cm}$ (Robert et al., 1997). Por outro lado, as variações observadas não apresentaram diferenças significativas.

O fluxo de calor metabólico é um inevitável produto secundário de todos os processos ligados ao crescimento (Criddle et al., 1991). Partindo-se desta base, uma maior emissão de calor está diretamente relacionada com um maior metabolismo da planta. É evidente que a atividade metabólica depende do estado de hidratação dos tecidos. Leite (2004) constatou, em gemas vegetativas de pessegueiro, uma correlação entre o aumento da umidade ponderal e da respiração com o início de brotação.

Os resultados obtidos não indicam deterioração das plantas em sete meses de armazenagem a $-2^{\circ} \mathrm{C}$, no que diz respeito à atividade metabólica ou à capacidade de crescimento da parte aérea. A partir de abril, observou-se, em algumas plantas da cv Gariguette, uma necrose no interior do rizoma (Figura 3), problema conhecido como "Necrose da cv. Gariguette". Essa necrose não é de origem patogênica, mas sim um distúrbio fisiológico correntemente observado em condições de armazenagem a $-2^{\circ} \mathrm{C}$. Outras variedades, como Elsanta, não apresentam este problema.

Os valores de Q $\left(20^{\circ} \mathrm{C}\right)$ na "Gariguette" são menores que na "Elsanta", atingindo, a 72 horas de aclimatação, um máximo de 28,7 
$\mu \mathrm{W} . \mathrm{mg}^{\mathrm{M}} \mathrm{MS}^{-1}$ e $33,42 \mu \mathrm{W} \cdot \mathrm{mgMS}^{-1}$, respectivamente. Mesmo comportamento foi observado na umidade ponderal (UP) e comprimento do pecíolo (CP) que são, respectivamente, na última data de determinação, de 4,6 e 12,4 cm, respectivamente, na "Gariguette" e de 5,6 e 13,5 cm na Elsanta. Estas diferenças poderiam ser relacionadas a uma menor quantidade de reservas (açúcares e amido), no fim da estocagem, na cv Gariguette em comparação à cv. Elsanta (Bigey, 2000), e/ou estar relacionadas com o problema de necrose que apareceu na primeira, mas não na segunda cultivar.

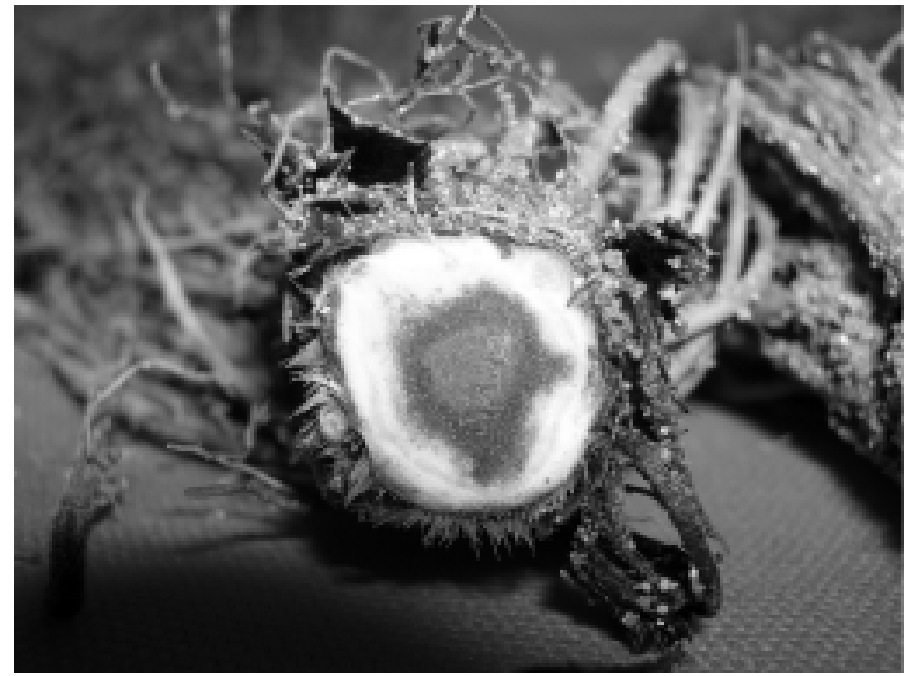

FIGURA 3 - Necrose no rizoma da planta da cv. Gariguette.

Uma evolução significativa do estado da parte aérea das plantas durante a estocagem a $-2^{\circ} \mathrm{C}$ pode ser deduzida dos diferentes valores medidos sem aclimatação e após aclimatação das plantas a $20^{\circ} \mathrm{C}$ durante 48 e 72 horas no que diz respeito aos parâmetros fluxo de calor metabólico, intensidade respiratória, umidade ponderal das zonas apicais. Os valores desses diferentes parâmetros são estreitamente correlacionados entre si.

As potencialidades metabólicas do ápice aumentaram durante as primeiras semanas de armazenagem no frio, e não se deterioraram ao longo dos oito meses de armazenagem, em ambas as cultivares.

A partir de quatro meses de armazenagem, ocorreu o aparecimento da necrose do rizoma em algumas plantas da cv. Gariguetti, mas não na cv. Elsanta.

\section{REFERÊNCIAS}

BIGEY, J. The search for a criterion for assessing the quality of cold stored strawberry plants. In: WG PLANT PHYSIOLOGY, 3., 2000, Ancova. Meeting... 9p.

CRIDDLE, R. S.; FONTANA, A. J.; RANK, D. R.; PAIGE, D.; HANSEN, L. D.; BREIDENBACH, R. W. Simultaneous measurement of metabolic heat rate, $\mathrm{CO} 2$ production, and $\mathrm{O} 2$ comsuption by microcalometry. Analytical Biochemistry, Orlando, v.194, p.413-417, 1991.

HANSEN, L. D.; LEWIS, E.A.; EATOUGH, D.J.; FOWLER, D.P.; CRIDDLE, R.S. Prediction of long-term growth rates of larch clones by calorimetric measurement of metabolic heat rates. Canadian Journal of Forest Research, Ottawa, v.19, p.606-611, 1989.

HANSEN, L.D.; TAYLOR, D.K.; SMITH, B.N.; CRIDDLE, R. S. The relation between plant growth and respiration: applications to ecology and crop cultivar selection. Russian Journal of Plant Physiology, Stutgart, v.43, n.6, p.691-697, 1996.

HENRY, F. Suivi des potentialités de croissance du fraisier par des méthodes microcalorimetriques et morphologiques. $1999.35 \mathrm{f}$. (Diplôme Universitaire Superior)- Université Blaise Pascal, Clermont Ferrand, 1999.

LEITE, G.B. Evolution des états des bourgeons et de leur hétérogénéité le long du rameau d'un an de pêcher sous différents régimes de températures après l'installation de l'endodormance. 2004. 168f. Thése (Doctorale des Sciences de la Vie et de la Santé) -Université Blaise Pascal, Clermont-Ferrand, 2004.

LIETEN, F.; KINET, J.-M.; BERNIER, G. Effect of prolonged cold storage on the production capacity of strawberry plants. Scientia Horticulturae, Amsterdanm v.60, p.213-219, 1995.

ROBERT, F. Recherche de marqueurs morphologiques et biochimiques de la dormance du fraisier(Fragaria $x$ ananassa Duch.).1996. $172 \mathrm{f}$. Thése (Doctorale des Sciences de la Vie et de la Santé) -Université Blaise Pascal, Clermont-Ferrand, 1996.

ROBERT, F.; PETEL, G.; RISSER, G.; GENDRAUD, M. Determination of the growth potential of strawberry plants (Fragaria $x$ ananassa Duch), by morphological and nucleotids measurements in the relation to chilling. Canadian Journal of Plant Science, Ottawa, v.77, p.127-132, 1997.

VERPONT, F. Incidence de la fertilisation azotée en pépinière. InfosCtifl, Paris, v.188, p.41-45, 2003. 